\title{
Aspectos editoriais e discursivos nas retraduções para o português de Alice's adventures in wonderland de Lewis Carroll ${ }^{1}$
}

\author{
Editorial and discursive issues in the retranslation of \\ Lewis Carroll's story Alice's adventures in wonderland \\ into Portuguese
}

Micla Cardoso de SOUZA ${ }^{2}$

UnB / EMBRAPA

Válmi HATJE-FAGGION ${ }^{3}$

Universidade de Brasília (UnB)

RESUMO: O objetivo deste artigo é mostrar como uma mesma obra pode ser traduzida de inúmeras maneiras, dependendo do projeto de tradução da editora e do tradutor. Com esse intuito, três traduções, para o português, da obra Alice's adventures in wonderland de Lewis Carroll, que foi retraduzida e publicada diversas vezes no Brasil, foram selecionadas para uma leitura comparativa. As traduções escolhidas foram: Alice no país das maravilhas da L\&PM Pocket (1998), traduzida por Rosaura Eichenberg e Ísis Alves; Alice: edição comentada da Jorge Zahar Editor (2002), traduzida por Maria X. de A. Borges; e Alice no país das maravilhas da Editora Ática (2006), traduzida por Ana Maria Machado. O esquema teórico para a descrição de traduções literárias de Lambert e Van Gorp (1985) serve de ponto de partida para a leitura comparada. Entretanto, como a obra traduzida inclui aspectos da cultura inglesa, presentes na narrativa por meio da intertextualidade, principalmente de alusões, trocadilhos e paródias, esses tópicos constituem o cerne da leitura comparativa. Os dados coletados indicam

\footnotetext{
'Este artigo está baseado na dissertação de Micla Cardoso de Souza (SOUZA, 2009).

${ }^{2}$ Brasil. E-mail: miclacsouza@gmail.com

${ }^{3}$ Universidade de Brasília, Departamento de Línguas Estrangeiras e Tradução, Campus Universitário Darcy Ribeiro, ICC Sul, Sala B1 167/63, Asa Norte, CEP 70910-900, Brasil. E-mail: hatjefaggion@yahoo.com
} 
que, apesar das semelhanças entre as traduções, os textos traduzidos apresentam diferenças e peculiaridades quando se considera os públicos leitores previstos e os participantes envolvidos no processo tradutório.

PALAVRAS-CHAVE: Intertextualidade. Participantes envolvidos. Práticas editoriais e discursivas. Retraduções.

ABSTRACT: The objective of this article is to show how a same text can be translated in different ways, depending on the translation project of the publisher and the translator. With this purpose, three translations in Portuguese of Lewis Carroll's story Alice's adventures in wonderland, which was retranslated and published in Brazil several times, were selected for a comparative reading. The translations chosen were: Alice no país das maravilhas published by L\&PM Pocket (1998) and translated by Rosaura Eichenberg and Ísis Alves; Alice: edição comentada published by Jorge Zahar Editor (2002) and translated by Maria X. de A. Borges; and Alice no país das maravilhas published by Editora Ática (2006) and translated by Ana Maria Machado. Lambert and Van Gorp's (1985) theoretical model for the description of literary translation is the point of departure of the comparative reading. However, since the translated story is characterized by cultural aspects of the English language, present in the narrative by means of intertextuality, mainly allusions, word puns and parodies, these topics are the focus of the comparative reading. The collected data indicate that, in spite of the similarities between the translations, the translated texts have their own differences and peculiarities when the expected reading public and people involved in the translation process are taken into account.

KEYWORDS: Intertextuality. Agents involved. Editorial and discursive practices. Retranslation.

\section{Introdução}

\section{Alice no Brasil: três traduções para o português}

[...] a tradução não trata apenas de palavras, mas de textos em situações (SNELL-HORNBY, 1988, p.131, tradução nossa) ${ }^{4}$

${ }^{4}[. .$.$] translation is not merely a matter of words, but of texts in situations$ (SNELL-HORNBY, 1988, p.131). 
Charles Lutwidge Dodgson, conhecido mundialmente por seu pseudônimo ${ }^{5}$ Lewis Carroll (1832-1898), foi um vitoriano "reservado, acadêmico nato, clérigo irrepreensível [...] conservador, formal, controlado [...] o protótipo de sua época e sua classe [...]" (COHEN, 1998, p.239). Segundo a Britannica online encyclopedia ${ }^{6}$, um homem de vários talentos: fotógrafo, especialista na teoria da lógica, matemático e escritor inglês. Durante toda a sua trajetória, foi dotado por um espírito criativo. Quando pequeno, escrevia poemas e histórias em casa e na escola. Depois, ao entrar na faculdade, além dos textos que já produzia, começou a publicar nesse meio. Discorreu a respeito de temas relacionados à matemática, publicando livros e panfletos sobre geometria, determinantes e assuntos afins na universidade de Oxford, na Inglaterra.

Seu reconhecimento como autor renomado, contudo, veio apenas com outro tipo de texto: o literário. Seu primeiro sucesso foi Alice's adventures in wonderland (1865), cuja fonte principal de inspiração foi a jovem Alice, uma das filhas de Henry Liddell, reitor de Oxford, universidade que Carroll frequentara e, mais tarde, na qual lecionara. Em seguida, o autor publicou a continuação dessa narrativa, Through the looking glass (1871), o poema The hunting of the Snark (1876), e a história Sylvie and Bruno (1889). As mais notórias destas histórias, entretanto, sempre foram as de Alice, principalmente o primeiro livro.

Essa narrativa começou a ser contada no dia 4 de julho de 1862 quando Carroll e seu amigo Robinson Duckworth, membro da Trinity College, levaram as irmãs Lorina, Alice e Edith Liddell

\footnotetext{
${ }^{5}$ Conforme Cohen (1998, p.349-350), Charles trocou seu nome porque temia que se os críticos soubessem que ele e "Lewis Carroll eram a mesma pessoa" e que "[...] poderiam receber com indiferença suas obras de matemática; de fato algumas resenhas de seus livros sérios assumiam um tom frívolo quando o autor ligava os dois nomes".

${ }^{6}$ Disponível em: <http://www.britannica.com/EBchecked/topic/97087/ LewisCarroll>.

${ }^{7}$ A obra também é conhecida pelo título reduzido, Alice in wonderland.
} 
para uma expedição no rio. Foi durante esse passeio de barco que Carroll deu asas a sua imaginação:

[...] aconteceu naquela "tarde dourada" do verão de 1862. As circunstâncias eram ideais: [Carroll] estava [...] na companhia das três irmãs Liddell, que tinham entre oito e treze anos, e Duckworth [...]. Lá [...] no mundo do bote, auto-suficientes, longe de família, governanta, sociedade, dever, estavam unidos por suas brincadeiras [...] seu riso espontâneo. "Conte uma história", ordenaram as pequenas sacerdotisas. E assim, ali mesmo, $[\ldots]$ criou a fábula da menina que cai na toca do coelho. (COHEN, 1998, p.159)

Foi esse o cenário que inspirou Carroll a narrar a história que se tornaria um grande sucesso da literatura infantil. Por esta razão, a história de Alice tem sido traduzida para diversos países, em diversas línguas ${ }^{8}$. As primeiras traduções foram para o alemão, o francês e o italiano, por volta de 1869. Cohen (1998, p.444) afirma que "os últimos anos da década de 1860 viram uma edição de Alice atrás da outra”. No Brasil, a primeira tradução e adaptação foi a de Monteiro Lobato, publicada inicialmente em 1931. Depois, houve uma sucessão de traduções ${ }^{9}$, cada uma voltada para públicos distintos. Como um clássico, a história de Alice pode ser e é lida e relida por pessoas de diversas idades, em fases distintas de suas vidas, e o tradutor é o principal responsável por intermediar essas leituras e releituras. Nesse sentido, reescreve a obra de partida para leitores de outra cultura (SNELL-HORNBY, 1988$, p.2) $)^{10}$.

${ }^{8}$ Machado (CARROLL, 2006, p.132) aponta que essa história foi traduzida para pelo menos 125 idiomas.

${ }^{9}$ A dissertação de Nilce Maria Pereira, Alice no Brasil-traduções, adaptações e ilustrações, defendida na Universidade de São Paulo, em 2003, apresenta nove traduções da obra de Carroll. Já Maria José Batista de Lima cita doze traduções e adaptações nas referências do seu artigo, A recepção crítica à obra Alice no país das maravilhas, após a adaptação de Monteiro Lobato.

${ }^{10}[. .$.$] the translator [...] who then recreates this whole for another readership$ in another culture. 
Desse modo, o texto de partida não pode ser considerado estático (SNELL-HORNBY, 1988, p.2)11, já que é reescrito sempre que surge a necessidade de alcançar outro público. Pode haver inúmeras traduções de uma mesma obra simultaneamente ou, então, as obras clássicas podem ser retraduzidas em épocas diferentes, como apontam Rónai (1981, p.117) e Schulte (1999) ${ }^{12}$. Foi esse o caso de Alice's adventures in wonderland. A obra foi reescrita várias vezes e, apesar das possíveis semelhanças entre suas traduções, nenhuma é igual à outra. Todas variam entre si porque foram escritas por tradutores diferentes, com sua própria história de vida e experiência profissional, e porque focam em receptores distintos.

Neste artigo, foram escolhidas três traduções ${ }^{13}$, em português, para uma leitura comparativa, tendo como base os receptores almejados e o ano em que foram publicadas (de 1998 a 2006). Decidiu-se trabalhar com traduções mais recentes para facilitar o contato com os tradutores e as editoras, para tratar do processo tradutório e da formulação final da obra traduzida. Assim, aspectos relevantes que dizem respeito às práticas editoriais $\mathrm{e}$ discursivas podem ser evidenciados.

A primeira tradução é uma publicação da L\&PM Pocket, uma coleção de livros de bolso, intitulada Alice no país das maravilhas. A edição foi impressa em 1998. A tradutora principal foi Rosaura Eichenberg, mas Ísis Alves participou da tradução dos poemas. O motivo desse procedimento, no entanto, não é explicitado e não há notas de rodapé nesse livro. O texto de partida

\footnotetext{
${ }^{11}[. .$.$] the text cannot be considered as a static specimen of language.$

${ }^{12}[\ldots]$ retranslations of foreign works can definitely contribute to a revival of interest in reading them; the study of the differences that become visible from one translation to the next affirms the necessity for new translations as a continuous effort to expand and deepen the act of reading and interpretation and to shed light on how cultures interpret their world at particular moments of history.

${ }^{13}$ Embora o autor da obra seja Lewis Carroll (1965, 1998, 2002, 2006), a partir daqui, será usado o nome do tradutor responsável pelo texto traduzido, para a discussão sobre as traduções.
} 
é considerado literatura infantil pela editora, porém, parece visar, também, um público mais geral, como indica a declaração na contracapa: "o mais estranho e fascinante livro para crianças (só para crianças?)" (CARROLL, 1998). Em entrevista ${ }^{14}$, o editor Ivan Pinheiro Machado ressalta que a ideia dessa coleção "é vender livros para os jovens. E isto pede sempre uma linguagem contemporânea".

A segunda tradução é uma reedição de Alice: edição comentada publicada em $2002^{15}$ pela Jorge Zahar Editor. De acordo com Mariana Zahar (2009), editora e neta do fundador da Jorge Zahar Editor, por causa das notas explicativas à margem do livro, essa "não é uma edição para criança", mas um exemplar para leitores adultos interessados em um estudo mais aprofundado sobre a obra de Carroll. Inclui as narrações Aventuras de Alice no país das maravilhas e Através do espelho. A obra de Carroll é considerada "ficção fantástica inglesa" e foi traduzida por Maria Luiza X. de A. Borges.

Aúltima tradução, Alice no país das maravilhas, é a terceira edição publicada pela Editora Ática, em $2006^{16}$. A tradutora é a, também autora, Ana Maria Machado, cujo nome aparece logo na capa. Um diferencial entre essa e as traduções anteriores é que, nessa publicação, o desenhista Jô de Oliveira introduz ilustrações baseadas na xilogravura usada nos cordéis, e a tradutora, canções e poemas conhecidos na cultura brasileira. O objetivo dessa tradução, segundo Machado (2009), é “dar ao público escolar o primeiro contato com grandes escritores". Por isso, não se trata de "uma tradução destinada ao deleite erudito de estudiosos adultos, com espaço para montes de comentários, anotações e notas ao pé de página" (MACHADO, 2009).

Neste artigo, foram comparadas determinadas passagens dessas traduções com o intuito de ilustrar algumas das dificuldades

14 Entrevista concedida por e-mail à Micla Cardoso de Souza em 04 de dezembro de 2008.

${ }^{15}$ A primeira edição foi oficialmente lançada em novembro de 2001.

${ }^{16}$ Essa tradução foi publicada pela primeira vez em 1997. 
encontradas pelas tradutoras Eichenberg, Alves, Borges e Machado. Essa comparação é feita a partir de um dos quatro níveis sugeridos por Lambert e Van Gorp (1985, p.42-53) ${ }^{17}$ para a descrição de traduções literárias: o da microestrutura textual. Esse nível inclui a seleção gramatical e as formas de discurso (direto ou indireto), enfim, as escolhas linguísticas adotadas pelas tradutoras. Porém, como a história de Alice faz referência a nomes e eventos característicos de outra cultura, os itens culturalmente carregados de significado são o foco principal dessa leitura comparativa (AIXELÁ, 1996).

A obra de Carroll inclui vários intertextos. Há alusões a personagens reais, elementos típicos da Era Vitoriana ${ }^{18}$ e situações vivenciadas pelo próprio autor, além de paródias de textos de escritores de sua época.

Conforme Charaudeau e Maingueneau (2004, p.289), esses intertextos constituem o "conjunto de fragmentos convocados (citações, alusões, paráfrase) em um corpus dado [...]”. Para

${ }^{17} \mathrm{O}$ esquema teórico de Lambert e Van Gorp (1985, p.42-53) divide-se em quatro estágios de análise comparativa: 1) dados preliminares, isto é, aspectos extratextuais de uma edição, como título, capa, data de publicação, folha de rosto, prefácio e notas; 2) macroestrutura, ou seja, a estrutura geral do texto, incluindo sua divisão em capítulos, parágrafos e frases; 3) microestrutura, a seleção lexical e gramatical dominantes, bem como o estilo e as formas de discurso (direto ou indireto) adotados; e 4) contexto sistêmico, a relação intertextual entre as traduções de uma mesma obra e o texto de partida, e a recepção e a função de cada tradução no contexto de chegada, que envolve o leitor e a crítica.

${ }^{18}$ A Era Vitoriana foi um período marcado por fortes contrastes. Durante o reinado da Rainha Vitória (1837-1901), a primeira monarca inglesa a ter seu nome relacionado ao seu reinado ainda em vida, houve grandes avanços nas áreas médica, científica, tecnológica, econômica e industrial. Nesse período, o Reino Unido também se firmou como uma potência marítima, tendo-se consolidado como um império colonial. Contudo, apesar de ter sido marcada por inúmeras conquistas, a Era Vitoriana também tem sido associada ao sentimento pudico e ao moralismo repressor vigentes na época por causa da forte religiosidade, presente no dia a dia dos vitorianos, ligada à ética, aos valores familiares, à fé e à religião cristãos (SHEPHERD, 2001). 
Kristeva (2005, p.66), “[...] todo texto se constrói como mosaico de citações, todo texto é absorção e transformação de um outro texto". A intertextualidade seria, portanto, uma forma de colorir e transformar um texto (LEPPIHALME, 1997, p.8) com base nas obras anteriores da mesma literatura (RÓNAI, 1981, p.63). Hatim e Mason (1990, p.120) concluem que a intertextualidade "[...] evoca áreas inteiras de nossa experiência textual prévia" ${ }^{19}$ porque dependem do conhecimento de texto relevantes em um sistema cultural.

Ao se considerar essas características da história de Alice, são quatro os aspectos culturais analisados neste artigo: a) nomes - os nomes dos personagens aludem a conhecidos de Carroll, ou seja, se associam a figuras relacionadas a aspectos históricos e culturais do período no qual o autor viveu, podendo ser carregados de significado, como destaca Theo Hermans (1988, p.11-13) ${ }^{20}$; b) títulos - Newmark (1988, p.56-57) ${ }^{21}$ aponta que os títulos podem se referir ao conteúdo de um texto, sendo, desse modo, alusivos. Neste caso, fazem referência ao tema do capítulo ao qual se referem, incluindo jogos de palavras na língua de partida; c) poemas - os textos recitados por Alice são paródias de poesias que as crianças inglesas precisavam saber de cor naquele tempo e de canções populares da Inglaterra Vitoriana, conhecidas pelos

19 [...] evoke whole areas of our previous textual experience (HATIM; MASON, 1990, p.120).

${ }^{20}$ Hermans (1988), em seu artigo "On translating proper names, with reference to De Witte and Max Havelaar", divide os nomes próprios em duas categorias: [...] conventional and loaded. Conventional proper nouns are those seen as "unmotivated" and thus as having no meaning themselves. Loaded proper names are those literary names that are somehow seen as "motivated"; they range from faintly "suggestive" to overtly "expressive" names and nicknames, and include those fictional as well as non-fictional names around which certain historical or cultural associations have accrues in the context of a particular culture.

${ }^{21}$ Com relação à tradução de títulos de obras ficcionais, Newmark (1988, p.57) faz uma distinção entre títulos descritivos e alusivos: I distinguish between 'descriptive titles', which describe the topic of the text, and 'allusive titles', which have some kind of referential or figurative relationship to the topic. 
contemporâneos de Carroll; e d) trocadilhos e nonsense - jogos entre palavras com significados diferentes, mas sons parecidos (FERREIRA, 1975, p.1412). O autor troca sentidos, brincando com o vocabulário da sua língua, o inglês, para divertir meninos e meninas vitorianos, mesmo quando se tratava de assuntos considerados mais sérios, como a educação (CARROLL, 2002, p.94).

Apenas alguns exemplos foram selecionados por não ser possível discorrer sobre todos detalhadamente, contudo, ainda indicam as tendências gerais de cada texto traduzido. A leitura comparativa a seguir ilustra os diferentes projetos de tradução de cada tradutora, isto é, suas escolhas tradutórias de acordo com seus propósitos e objetivos (BERMAN, 1995).

\section{Leitura comparativa - aspectos culturais e intertextuais}

\subsection{Nomes}

Na história de Carroll (1965), os nomes próprios e substantivos comuns, escritos com letra inicial maiúscula, são usados para denominar personagens ao exprimir suas qualidades e características descritivas. Cada um desses nomes que aparece na obra pode ser considerado alusivo porque carrega uma significação específica e, na maioria das vezes, se refere às pessoas com as quais o autor conviveu. Por exemplo, os nomes Dodo, Duck, Lory, Eaglet e Alice que aparecem no livro se referem ao próprio Lewis Carroll, seu amigo Robinson Duckworth, à Alice e a suas duas irmãs, Lorina e Edith - participantes do passeio de bote que inspirou a narrativa do autor.

As três tradutoras lidam com os dois primeiros nomes de maneira bastante similar. Duck foi traduzido como "Pato", e Dodo tornou-se "Dodô". Eichenberg (CARROLL, 1998) foi a única que não incluiu o acento no último "o" da palavra. Alice continuou sendo "Alice", ou seja, o nome foi apenas transcrito. 
Já a tradução dos demais nomes, Lory e Eaglet, variam e indicam melhor as diferenças entre os textos traduzidos.

Em inglês, Lory, conforme o dicionário The American heritage (1996, p.1062), é um tipo de papagaio australiano e Eaglet é uma jovem águia. Eichenberg mantém a primeira parte do conceito de Lory ao optar por "Papagaio". Em relação à Eaglet, prefere utilizar "Aguiazinha", o diminutivo de "Águia", como nome do personagem. Assim, as palavras que escolhe para sua tradução são, de modo geral, de fácil compreensão para a maioria dos leitores. Por esse motivo, sua tradução tem sido considerada a mais abrangente dessas traduções.

De forma semelhante, Borges (CARROLL, 2002) traduz Lory como "Papagaio". No entanto, como seu público é mais erudito, ao se considerar as notas explicativas à margem da tradução, em vez de utilizar "Aguiazinha", a tradutora elege o diminutivo irregular da palavra "Águia", "Aguieta", para traduzir o nome - provavelmente não tão familiar para o receptor comum.

Machado (CARROLL, 2006), ao escrever tendo em mente o leitor infanto-juvenil, adota o termo "Periquito", ave um pouco menor, mas pertencente à mesma família que a do papagaio, a dos psitacídeos. Quanto à Eaglet, decide usar a expressão "Filhote de Águia", descrevendo o personagem com mais palavras. Ao longo desse trecho, Machado (CARROLL, 2006) busca utilizar uma linguagem mais voltada para crianças e adolescentes, como em "animaizinhos", "bichos", "turma" e "praia", apesar de ter utilizado o vocábulo "apinhada" - referente a "cheio, amontoado, superlotado ou aglomerado" (FERREIRA, 1975, p.115) presente, também, na tradução de Borges.

\subsection{Títulos}

A obra de Carroll (1965) inclui um total de doze títulos. Todos aludem ao conteúdo do capítulo ao qual se referem, enquanto outros abrangem acontecimentos externos à história e/ ou jogos de palavras. O título do Capítulo 3, A caucus-race and 
a long tail (CARROLL, 1965, p.31), por exemplo, é alusivo e contém um jogo de palavras, como será explicado a seguir. Foi traduzido como: A corrida-caucus e uma longa história (CARROLL, 1998, p.35); "Uma corrida em comitê e uma história comprida" (CARROLL, 2002, p.27); e "Um corre-corre e uma história comprida" (CARROLL, 2006, p.30).

Nessa parte da história, Alice e as outras criaturas que estavam dentro da poça/lagoa formada por suas lágrimas finalmente conseguem sair de lá, mas estão todos encharcados. Após uma tentativa frustrada de se secarem, o Dodô finalmente sugere que a melhor maneira de fazerem isso é com uma corrida, a caucus-race, e logo ensina os outros como devem fazer: correr em círculos desordenadamente até chegar a hora de parar, que é ele quem vai determinar. É bastante provável que essa expressão, caucus-race, aluda a:

[...] um sistema de organização partidária extremamente disciplinada por comitês. [...]. Carroll pode ter pretendido que sua "corrida em comitê" simbolizasse o fato de que os membros de comitês geralmente correm muito em círculo, sem chegar a lugar algum, todos almejando um prêmio político. (CARROLL, 2002, p.28)

Já a segunda parte do título tem um sentido bastante ambíguo. A palavra tail (rabo ou cauda em inglês), soa como tale (conto, história). Nesse capítulo, um dos personagens, o Camundongo (Mouse), convidado a contar a sua história, anuncia: mine is a long and sad tale! Apesar de afirmar que sua história é longa e triste, Alice confunde os sons das palavras tail e tale, e acredita que ele está se referindo ao seu rabinho. Por isso, ela olha para a cauda do Camundongo e observa que de fato é comprida, mas não entende por que seria triste (CARROLL, 1965, p.39).

Eichenberg (CARROLL, 1998, p.35) traduz o título como A corrida-caucus e uma longa história. Na sua tradução, o nome da corrida é transcrito, mas não há nenhuma explicação de como seria ou ao que aludiria. Quanto à segunda parte, a tradutora destaca apenas um de seus sentidos, o de uma história longa que 
será contada pelo Camundongo. Apesar de esse adjetivo poder descrever a cauda do Camundongo, aqui não permanece o mesmo jogo de palavras que o no texto de Carroll.

O título escolhido por Borges é: Uma corrida em comitê e uma história comprida. Sua opção por "comitê" mostra, pelo menos em parte, a natureza da corrida. $\mathrm{O}$ termo se refere a um grupo de pessoas com funções específicas e aos grupos das câmaras legislativas responsáveis por estudar e dar pareceres em relação às propostas de lei e projetos (FERREIRA, 1975, p.351)22. Muitas vezes, esse é um processo demorado, sem soluções diretas. Na segunda parte do título, a tradutora opta por uma estratégia parecida com a de Eichenberg, adotando a tradução: "uma história comprida".

Machado (CARROLL, 2006, p.30) traduz o título do Capítulo 3, como: Um corre-corre e uma história comprida. A primeira expressão utilizada, "corre-corre", ilustra bem o que Alice e as outras criaturas fizeram até se secar, mas não inclui o aspecto político do título. A tradutora parece, então, preferir uma linguagem mais coloquial tendo em mente seu leitor de chegada, o público infanto-juvenil. Ela traduz o final do título da mesma forma que Borges, como: "uma história comprida", mantendo parte do jogo de palavras.

\subsection{Paródias}

Na obra de Carroll, há a presença constante de vozes de outros autores. Os inter(textos) recitados por Alice são paródias de poemas ou canções populares da Inglaterra Vitoriana, conhecidos pelos contemporâneos de Carroll, inclusive pelas crianças. É uma forma alusiva que o autor encontrou para reescrever textos de sua época. A seguir, será apresentado um exemplo de como as tradutoras lidaram com esse aspecto do texto de partida.

${ }^{22}$ Ver verbete "comissão", uma das definições de “comitê" em Ferreira (1975, p.351). 
No Capítulo 7, A mad tea-party, Alice participa de um chá muito louco. O personagem do Chapeleiro se recorda de uma música que havia cantado para a Rainha de Copas e que quase lhe custara a vida porque, segunda ela, ele não estava mantendo o compasso e sim matando o tempo (CARROLL, 2002, p.71-72). Essa é uma alusão à primeira estrofe do poema de Jane Taylor, com versos heptassílabos e rima $a a b b$ :

Twinkle, twinkle, little star

How I wonder what you are!

Up above the world so high,

Like a diamond in the sky! $!^{23}$

Parodiado pelo Chapeleiro, soa um pouco diferente:

Twinkle, twinkle, little bat!

How I wonder what you're at!"

[...]

Up above the world you fly,

Like a tea-tray in the sky.

(CARROLL, 1965, p.110)

Como indicam as traduções:

'Pisque, pisque morceguinho!

O que faz aí sozinho?'

[...]

'Sobre o mundo voa ao léu,

Bandeja de chá no ceú.'

(CARROLL, 1998, p.96)

Pisca, pisca, ó morcego!

Que eu aqui quero sossego!

[...]

${ }^{23}$ Tradução do poema encontrada em Alice: edição comentada (CARROLL, 2002, p.72):

Pisca, pisca estrelinha,

Quisera saber o que és!

Acima do mundo, tão alta,

Qual diamante no céu. 
Por sobre o mundo você adeja

Qual chá numa grande bandeja.

(CARROLL, 2002, p.71)

Meu limão, meu mamoeiro, meu chá de maracujá...

$[\ldots]$

Uma vez chá do Lelê

outra vez chá do Lalá

(CARROLL, 2006, p.75)

No lugar da "estrelinha" do poema de Taylor, Carroll apresenta um "morcego". Na biografia de Carroll, Cohen (1998, p.72) explica que esse episódio se relaciona a uma situação vivenciada pelo próprio autor. Certa vez, quando estava entretendo um grupo de crianças com uma de suas invenções, um morcego voador, na universidade de Oxford, houve um pequeno incidente. $\mathrm{O}$ morcego saiu voando pela janela de seu apartamento e aterrissou em uma bandeja de chá, que estava sendo carregada por um dos empregados da instituição. Assustado, ele arremessou a bandeja pelos ares.

Essa é a história retratada no poema de Carroll (CARROLL, 1965, p.110). O evento é apresentado em duas estrofes de dois versos. Na primeira estrofe, segundo verso, How I wonder what you're at, questiona-se o que o morcego estaria aprontando. Depois, nos dois primeiros versos da segunda estrofe, Up above the world you fly, Like a tea-tray in the sky, aponta-se que está voando por sobre a terra, como uma bandeja de chá no céu, referindo-se ao fato ocorrido naquele dia em Oxford, como mencionado acima. Na paródia, os dois primeiros versos rimam um com o outro, com bat e at, e os dois últimos também, com fly e $s k y$, criando uma rima $a a b b$. São sete sílabas por verso, como ocorre no poema de Taylor.

Eichenberg e Alves (CARROLL, 1998, p.96) seguem o mesmo formato do poema de Carroll, com duas estrofes de dois versos rimando entre si. As tradutoras adotam a mesma rima que o 
autor, $a a b b$ - "morceguinho" e "sozinho" rimam, do mesmo modo que "ao léu" e "céu". Além disso, o poema delas continua tendo versos heptassílabos. Quanto ao conteúdo do poema de partida, há poucas mudanças. No primeiro verso, a palavra twinkle, que indica a ação de brilhar, é traduzida por "pisque", imperativo afirmativo da terceira pessoa do singular do verbo "piscar". No segundo, o diminutivo little bat é mantido com "morceguinho". Contudo, o verso é transformado em uma pergunta, "O que faz aí sozinho?" Nesse caso, as tradutoras criam uma rima rica entre o substantivo "morceguinho" e o adjetivo "sozinho". No primeiro verso da segunda estrofe, adicionam o adjunto adverbial, "ao léu", que significa "à vontade" (FERREIRA, 1975, p.832), ao sentido de "voa". Essa expressão passa a rimar com o substantivo "céu", formando mais uma rima entre palavras de classes gramaticais diferentes.

Borges (CARROLL, 2002, p.71) recria a rima dos versos de Carroll $(a a b b)$ com um número idêntico de sílabas. De modo similar a Eichenberg e Alves, a tradutora modifica o segundo verso da primeira estrofe. Já não se questiona mais o paradeiro do morcego, mas afirma-se que se quer "sossego". É provável que a tradutora tenha feito essa mudança para poder rimar este substantivo com o anterior, "morcego", vocábulo em sua forma canônica, diferente do diminutivo "morceguinho" utilizado pelas tradutoras da edição da L\&PM Pocket. Borges prefere traduzir twinkle como "pisca", imperativo afirmativo da segunda pessoa do singular do verbo "piscar". Em relação à segunda estrofe, segue a temática do poema de Carroll, uma vez que apresenta um morcego voador. Porém, Borges adota um vocabulário um pouco mais formal. Substitui "voar" pela palavra "adeja", do verbo "adejar", que significa "bater as asas; voar" (FERREIRA, 1975 , p.35), e altera o conteúdo do último verso do seu poema. Apresenta uma concepção distinta da dos versos de partida - o morcego não é comparado a uma bandeja voando pelo céu, mas ao "chá numa grande bandeja". Possivelmente, a tradutora buscou criar uma rima entre "bandeja" e "adeja". 
Machado (CARROLL, 2006, p.75), por sua vez, opta por parodiar uma canção popular brasileira ao traduzir o poema de Carroll. Sua tradução alude à cantiga de roda Meu limão, meu limoeiro com quatro versos de sete sílabas:

$$
\begin{aligned}
& \text { Meu limão, meu limoeiro } \\
& \text { Meu pé de jacarandá } \\
& \text { Uma vez, tindolelê } \\
& \text { Outra vez, tindolalá }
\end{aligned}
$$

A partir dessa canção, a tradutora cria um poema de duas estrofes com versos brancos, de sete sílabas cada um, não rimados, o que o distingue do poema de Carroll e do das outras tradutoras. Apesar de destacar a palavra "chá", sua tradução difere das outras porque seu poema de partida é diferente. No primeiro verso, "limoeiro" é substituído por "mamoeiro", e, no segundo, "pé de jacarandá" torna-se "chá de maracujá", referindo-se ao vocábulo tea do poema de Carroll. Na próxima estrofe, "tindolelê" e "tindolalá" são trocados por "chá do Lelê" e "chá do Lalá" não há referência à história do morcego, nem à bandeja voadora. O enfoque, porém, da tradutora não é o conteúdo do poema de Carroll, mas sim a sensação de que um poema ou canção da cultura de chegada está sendo recitado de forma errônea.

\subsection{Trocadilhos e nonsense}

Aolongo de suahistória, Carroll utiliza diversos trocadilhos, quando joga com palavras com significados diferentes, mas sons parecidos (FERREIRA, 1975, p.1412), como já foi observado. O autor troca sentidos, brincando com o vocabulário da sua língua, o inglês. Apesar de grande parte das crianças de sua época não conhecerem o significado de todas as palavras de sua obra, elas se divertiam com a sonoridade dos vocábulos e eram envolvidas pela narrativa das aventuras de Alice. Por meio desses trocadilhos, Carroll cria situações e diálogos aparentemente sem sentido e sem pé nem cabeça ${ }^{24}$, ou seja, de puro nonsense.

${ }^{24}$ Isso se não se levar em consideração os elementos intertextuais que são 
No Capítulo 6, Pig and pepper, Alice se encontra com a Duquesa que declara que o mundo giraria bem mais rápido se todos cuidassem da sua própria vida (CARROLL, 1965). Alice discorda e, para demonstrar seu conhecimento, aponta que se o mundo girasse mais depressa não seria vantajoso porque os dias e as noites passariam voando. A menina esclarece que a terra leva 24 horas para girar em torno de seu eixo: "You see the earth takes twenty-four hours to turn round on its axis" (CARROLL, 1965, p.90). Em inglês, a palavra axis, "eixo", é homófona à axes, "machado". Então, ao ouvir o primeiro termo axis, a Duquesa se lembra de axes e manda cortarem a cabeça de Alice: "Talking of axes, said the Duchess, chop off her head!" (CARROLL, 1965, p.90). Felizmente para a menina, a única pessoa adulta por perto, a cozinheira, continua preparando sua sopa apimentada sem prestar atenção às ordens de sua patroa.

Eichenberg repete a informação apresentada por Alice, acrescentando uma explicação adicional: "Veja, a Terra leva vinte e quatro horas para girar ao redor do seu eixo, o que é um achado [...]" (CARROLL, 1998, p.79). É possível que a tradutora tenha optado por incluir essa última frase em sua tradução, porque, em português, o som de "eixo" não lembra o de "machado", como axis e axes. Portanto, nessa tradução, após ouvir a explicação de Alice, a Duquesa retruca: “"Falando de machados' [...] 'corte a cabeça dela!'” (CARROLL, 1998, p.79). A Duquesa, rude e imponente, ao escutar "achado", ouve o que quer e pensa logo em "machados", embora, na narrativa de Carroll e nessa tradução, o contexto mostrar claramente de que não se tratava de axes, "machados", mas sim de axis, "eixo", ou, nesse caso, de "achado".

Borges apresenta uma tradução diferente para a fala de Alice: "Veja, a Terra leva vinte e quatro horas para completar sua revolução [...]" (CARROLL, 2002, p.59). Não inclui a palavra "eixo" no trecho traduzido, mas ainda mantém a essência do texto de Carroll. "Revolução", nesse caso, significa "rotação", "giro" (FERREIRA, 1975, p.1235), isto é, o movimento que a Terra faz

relevantes para a compreensão da obra. 
ao redor de seu eixo e que dura por volta de 24 horas (FERREIRA, 1975, p.1249). Entretanto, esse vocábulo inclui ainda outro sentido, logo adotado pela Duquesa: "Por falar em revolução", disse a Duquesa, "Cortem-lhe a cabeça" (CARROLL, 2002, p.59) - essa frase, mais formal em relação ao "Cortem a cabeça dela" (CARROLL, 1998, p.79) de Eichenberg, ressalta, novamente, o público adulto almejado por Borges. Aqui, a tradutora apresenta um jogo de palavras um pouco diferente do de Carroll. Um único vocábulo é usado para transmitir dois sentidos. O termo revolução também faz referência a "rebeliões e revoltas" (FERREIRA, 1975, p.1235), normalmente bastante violentas. O leitor que conhece a história das revoluções e sabe qual o papel que a guilhotina poderia exercer entende porque a Duquesa manda cortar a cabeça de Alice ao ouvir a palavra "revolução".

$\mathrm{Na}$ tradução de Machado (CARROLL, 2006), Alice não utiliza a expressão you see, "Veja", incluída nas traduções de Eichenberg e Borges. A menina segue direto para sua explicação: "Porque, se a terra leva vinte e quatro horas para girar em torno de seu eixo [...]" (CARROLL, 2006, p.63). A sentença termina, portanto, no mesmo ponto que o texto de partida, em axis. Como a palavra, em português, não rima com "machados", a tradutora cria outro trocadilho. Faz uma rima entre "eixo" e "queixo". A Duquesa não se refere a "machado", axes, mas ao "queixo" da menina, e comanda: "E por falar em seu queixo - disse a Duquesa - cortem a cabeça dela!" (CARROLL, 2006, p.63). Essa tradução, como a de Eichenberg, apresenta uma linguagem mais simples dirigida a um grupo de leitores jovem, o infanto-juvenil.

Os trechos analisados destacam, portanto, a dinâmica do processo tradutório e a importância do projeto de tradução de cada editora e tradutora na elaboração dos textos traduzidos, ressaltando como um único texto pode ser traduzido inúmeras vezes para que leitores diferentes entrem em contato com uma mesma obra. Assim, não há apenas uma tradução adequada ou perfeita (SNELL-HORNBY, 1988, p.2) 25. Há sim traduções diversas, com

${ }^{25}$ [...] This dynamic process explains why new translations of literary works 
objetivos distintos, voltadas para públicos diferentes. Em outras palavras, as traduções analisadas são reescrituras de um texto de partida que variam de acordo com os propósitos das editoras e dos tradutores envolvidos e com o público leitor previsto.

No prefácio geral dos editores da série Routledge, André Lefevere e Susan Bassnett, destacam que uma tradução é entendida como "[...] uma reescritura de um texto de partida e que todas as reescrituras, quaisquer que sejam suas intenções, refletem certa ideologia e poética e como tal manipulam a literatura para funcionar em uma sociedade de uma determinada maneira ${ }^{26}$ " (LEFEVERE, 1992, p.7, tradução nossa).

\section{Considerações finais}

Conforme foi apresentado, podem ser detectadas diversas semelhanças e diferenças entre as três traduções descritas, neste artigo, de Alice's adventures in wonderland. Como cada tradução ocorre em um determinado tempo e espaço, pode ser considerada única e difere uma da outra porque é voltada para leitores distintos, tendo funções específicas em dado contexto.

É o leitor quem usufrui dessa diversidade textual porque passa a ter acesso a diversas reescrituras da história de Alice, ou seja, há inúmeras opções de leitura deste clássico infantil. No caso dessas três traduções, cada uma oferece uma oportunidade diferente de o público interagir com o texto de partida. As práticas editoriais e discursivas revelam que a narrativa de Carroll pode ser lida sem notas e explicações adicionais, como na tradução de Eichenberg; com informações extras para um estudo detalhado da obra, como na tradução de Borges; ou, então, com a inclusão de referências conhecidas na cultura de chegada, neste caso a brasileira, como na tradução de Machado. Dessa forma, cada

are constantly in demand, and why the perfect translation does not exist.

${ }^{26}$ Translation is [...] a rewriting of an original text. All rewritings, whatever their intention, reflect a certain ideology and a poetics and as such manipulate literature to function in a given society in a given way. 
uma dessas traduções é recomendada para situações diferentes. A tradução de Eichenberg (CARROL, 1998), por exemplo, tem sido sugerida como leitura para alunos do ensino médio, pois permite que o leitor tenha contato direto com a história de Carroll. A de Machado (CARROLL, 2006) também é indicada para a leitura escolar, mas por outro motivo: acrescenta um sabor brasileiro às aventuras de Alice, aproximando-se mais dos jovens leitores do país. Já a tradução de Borges é ideal para estudos acadêmicos, ou seja, para os interessados em aprender mais sobre as entrelinhas da obra de Carroll. Assim, a tradução de Eichenberg e Borges se aproxima mais do autor e do texto de partida, enquanto a de Machado se volta para o leitor de chegada.

Os exemplos examinados ao longo deste artigo são uma amostra não prescritiva dos caminhos seguidos pelas tradutoras Eichenberg, Alves, Borges e Machado. Isto é, uma espécie de inventário dos problemas, soluções e motivações envolvidos em cada tradução, que mostram como essas tradutoras lidaram com certos problemas, sob quais circunstâncias e com quais resultados. Além disso, servem ainda para indicar novas possibilidades de tradução.

Contudo, ainda há muito que pesquisar. Falta, por exemplo, examinar se o público leitor alcançado por essas traduções realmente foi aquele previsto pelas editoras e tradutoras, se outros receptores se interessaram pela obra e como os leitores reagiram de fato aos diferentes projetos de tradução. Essas são apenas algumas das questões que poderiam ser investigadas para continuar desenvolvendo esse tema.

\section{REFERÊNCIAS}

AIXELÁ, J. Culture-specific items in translation. In: ÁlVAREZ, R; VIDAL, M. C. (Org.). Translation power subversion. UK: Multilingual Matter, 1996. p. 52-78.

BRITANNICA online encyclopedia. Disponível em: $<$ http://www.britannica. com/EBchecked/topic/97087/Lewis-Carroll>. Acesso em: 18 fev. 2009. 
BERMAN, A. Pour une critique des traductions: John Donne. Paris: Gallimard, 1995.

CARROLL, L. Alice's adventure in wonderland. Great Britain: Macmillan and Company Limited, 1965.

. Alice: edição comentada. Tradução Maria Luiza X. de A. Borges. Rio de Janeiro: J. Zahar, 2002.

- Alice no país das maravilhas. Tradução Ana Maria Machado. São Paulo: Ática, 2006.

- Alice no país das maravilhas. Tradução Rosaura Eichenberg. Porto Alegre: L\&PM, 1998.

CHARAUDEAU, P.; MAINGUENEAU, D. Dicionário de análise do discurso. Tradução Fabiana Komesu. São Paulo: Contexto, 2004.

COHEN, M. Lewis Carroll: uma biografia. Tradução Raffaella de Filippis. Rio de Janeiro: Record, 1998.

FERREIRA, A. Novo dicionário da língua portuguesa. Rio de Janeiro: Nova Fronteira, 1975.

HATIM, B.; MASON, I. Discourse and the translator. London; New York: Longman, 1990.

HERMANS, T. On translating proper names, with reference to De Witte and Max Havelaar. In: WINTLE, M. (Ed.). Modern Dutch studies. London: Athlone, 1988, p. 11-13.

KRISTEVA, J. Introdução à semanálise. Tradução Lúcia Helena França Ferraz. 2. ed. São Paulo: Perspectiva, 2005.

LAMBERT, J.; VAN GORP, H. On describing translations. In: HERMANS, T. (Ed.). The manipulation of literature: studies in literary translation. New York: St. Martin's Press, 1985. p. 42-53.

LEFEVERE, A. Translation, rewriting, and the manipulation of literary fame. London; New York: Routledge, 1992.

LEPPIHALME, R. Culture bumps: an empirical approach to the translation of allusions. UK: Multilingual Matters, 1997. 
LIMA, M. de. A recepção crítica à obra Alice no país das maravilhas, após a adaptação de Monteiro Lobato. Disponível em: <http:/www. alb.com.br/anais16/sem08pdf/sm08ss05_01.pdf >. Acesso em: 03 set. 2008.

MACHADO, A. M. Tradução de Alice no país das maravilhas. 2009. Entrevista concedida à Micla Cardoso de Souza, Brasília, 10 jan. 2009.

MACHADO, I. Alice no país das maravilhas. Edição de bolso. 2008. Entrevista concedida à Micla Cardoso de Souza, Brasília, 04 dez. 2008.

NEUBERT, A. Theory and practice of translation studies revisited: 25 years of translator training in Europe. In: BEEBY, A.; ENSINGER, D.; PRESAS, M. (Ed.). Investigating translation: selected papers from the 4th international congress on translation, Barcelona, 1998. Amsterdam; Philadelphia: J. Benjamins Publishing, 2000.

NEWMARK, P. A textbook of translation. UK: Prentice Hall International, 1988.

PEREIRA, N. M. Alice no Brasil: traduções, adaptações, ilustrações. Dissertação (Mestrado em Estudos Linguísticos e Literários em Inglês) - Universidade de São Paulo, São Paulo, 2003.

RÓNAI, P. As falácias da tradução. In: . A tradução vivida. 3. ed. Rio de Janeiro: Nova Fronteira, 1981. p. 110-128.

SCHULTE, R. The Helen and Kurt Wolff translation prize and the retranslation of literary works, Translation Review, vol. 57, 1999, p. $1-2$.

SHEPHERD, A. Overview of the Victorian Era. History in focus. Issue 1: the Victorian Era. Disponível em: <http://www.history.ac.uk/ihr/ Focus/Victorians/article.html>. Acesso em: 31 mar. 2009.

SNELL-HORNBY, M. Translation studies: an integrated approach. Amsterdam; Philadelphia: J. Benjamins, 1988.

SOUZA, M. C. Percursos tradutórios de três traduções em português de Alice's adventures in wonderland. Dissertação (Mestrado em Linguística Aplicada) - Universidade de Brasília, Brasília, 2009. 
THE American Heritage: dictionary of the English language. 3. ed. Houghton Mifflin Company: Boston and New York, 1996.

ZAHAR, M. Alice: edição comentada. 2009. Entrevista concedida à Micla Cardoso de Souza, Brasília, 02 jan. 2009.

Recebido em 30/03/2013.

Aprovado em 17/10/2013. 